\title{
Filozofia ca încercare de întemeiere si gasire a unui sens pentru modernitate
}

\author{
Dorin Stoica \\ Master in Philosophy, University of Quebec in Montreal
}

Rezumat : Ceea ce intentinam sa aratam prin parcurgerea succinta a cinci mari gânditori (Descartes, Kant, Hegel Husserl si Heidegger) este ca filzofia autentica trebuie sa ramâna totdeauna o forma de insertie în concret, astfel încât principiul libertatii, atât de pretios modernitatii, sa se realizeze pe sine în mod responsabil. Eforturile contemporane pentru întemeierea unei lumi mai bune pot fi duse la bun sfârsit daca vom pune în practica ceea ce filozofia a încercat prin reprezentantii ei cei mai de seama : sa fundamenteze cu luciditate si responsabilitate directia de construire a unei lumi constiente de implicatiile ei multiple. Scopul unei asemenea prezentari este de a face cu putinta dialogul, deliberarea si punerea în actiune a unor acte care sa genereze o dezvoltare durabila si cu cât mai putine riscuri. Apelul la un tip de transcendenta pe care sa o percepem nu ca pe o substanta exterioara ci ca pe o sacralitate existenta în noi, ar putea servi de asemenea scopurilor mentionate mai sus.

Ma bucur sa putem discutam astazi însemnatatea si rolul pe care le-ar putea avea filozofia în raport cu problemele ridicate de era globalizarii, a multipelor transformari si inovatii, heteromobilitatii accelerate, internetului, tehnologiei nucleare, agriculturii intensive, bioeticii, clonajului, economiei galopante, dezradacinarii maselor, dezvoltarii durabile, eugenismului, ireversibilitatii temporale, terorismului, responsabilitatii, ratiunii, libertatii, demnitatii umane.

Intrebarea care se naste nemijlocit din întalnirea cu toate aceste "'creatiiprobleme", enumerate, este urmatoarea : poate filosofia în forma sa actuala în care nu mai este reprezentata de nici un sistem speculativ închegat care sa conduca la cunoastere, esteticà si moralitate absolute, sa indice sensul unei noi orientari fundamentate pe normele pure ale ratiunii si demnitatii umane? Poate ea construi o critica constructiva, izvorata din redescoperirea propriilor ei fundamente: adevarul, binele, frumosul, astfel încât sa redam vietii si umanismului, sensul spiritual care le sunt proprii? Dar mai ales potrivit idealului sau de iubire de întelepciune poate filosofia sa coboare în modernitatea actuala ca stiinta atotcuprinzatoare capabila sa unifice diversitatea descoperirior naturale, aratând clar ca sensul lor legitim este conservarea umanismului si a demnitatii ca scopuri în sine. Poate ea sa reîntemeieze idealurile Reformei, ale Renasterii, Iluminismului, întelese ca fundamente pentru aventura modernitatii?

Stim cu totii cât de circumspecti sunt astazi însisi filozofii modernitatii în privinta fundamentului si a unei filozofii întemeiate pe radicalitatea Cogito-ului cartezian, pe Dumnezeul creator, sau pe Fiinta parmenidiana. Filozofii de astazi sunt dispersati în spatiul vid al lipsei de fundament al unei lumi accelarate si urgente. Ei se afla în situatia, împreuna cu toate celelalte discipline, de a nu mai putea indica forma tipica dupa care fiecare disciplina sa se fundamenteaze si cu atât mai putin adevarul dupa care toate aceste discipline trebuiesc legate împreuna astfel 
încat descopririle lor sa fie dirijate spre binefacerile omului.

$\mathrm{Si}$ totusi, oricât de dispersate si diversificate ar fi opiniile filozofilor in incapacitatea lor de a indica o întemeire, exista negresit o definitie a termenilor $\mathrm{cu}$ ajutorul carora ne exprimam si o gramatica prin care ne facem mai clare si mai consolidate mesajele lingvistice si astfel ne facem întelesi. Aceasta ne face sa întelegem ca exista, contrar aparentelor, o sursa, în esenta gandirii întemeietoare, care sa faca posibila conexiunea notiunilor în asa fel încat atât cel care se exprima cât si cel care recepteaza sa întelega sensul obiectiv valabil al unui mesaj. Sa fie acest fundament de comunicare o treapta catre gasirea unui sens al unei noi întemeieri?

Desigur, în viata curenta si în dezbaterile accelerate ale modernitatii, ne întalnim cu o serie de teorii aparute sub presiunea evenimentelor care ne depasesc prin viteza lor si astfel aceste teorii nu-si pot extrage esenta din forma pura a adevarului sau întelepciunii, asa cum ar fi de dorit pentru o filozofie fundamentata. Dar tocmai aceasta capacitate de constientizare a situatiei limita în care suntem pusi când decidem precipitat sub presiunea eficientei si a realizarii de sine sau a progresului nedefinit, ne lumineaza asupra problemei dezvoltarii durabile, ca fiinte demne si responsabile fata de provocarile lumii actuale.

Imaginea unor transcendente care ne depasesc, zeii, vin de pe filonul culturii grecesti, aceea a unei unice transcendente prin cultura iudaica, iar aceea unui Dumnezeu care se exprima pe sine în cele trei ipostaze ale Sale, Sfanta Treime, prin cultura crestina. Pentru Europa crestina si pentru civilizatiile occidentale de astazi care au atins un anumit grad de prosperitate, democratie si libertate, acest fapt este incontestabil si determinant. Numai într-o cultura în care Dumnezeu nea creat liberi prin acordarea alegerii între bine si rau putea sa se se nasca si sensul mai adânc al libertatii responsabile.

Înercând sa explice sensul procesualitatii istorice, Hegel arata ca formele succesive ale libertatii se depasesc unele pe altele pentru a ajunge la forma ideala realizata, împlinita. $\mathrm{Cu}$ toate acestea, nu trebuie decât sa luam cunostinta si sa fim sensibili la formele precare, la esecuri, la ratari si la ampla suferinta a atâtor oameni, chiar si în societatile avansate social, economic si politic pentru a avea o pozitie critica fata de acesta viziune finalista. $\mathrm{E}$ posibil ca historia sa nu-l fi înteles bine pe Hegel, însa nazismul si comunismul, care au urmat în timp viziunii hegeliene, infirma edificarea statului modern, asa cum îl concepuse filozoful idealismului absolut.

Lumea moderna prinde contur în mod explicit prin filozofia lui Descartes (15961650). El acorda filozofiei un rol precumpanitor, considerând-o ca fiind unitate a tuturor stiintelor. Însa ca ea sa-si realizeze rolul sau fundamental, este necesara o reconstructie a ei, orientata catre subiect. Unica sursa din care poate lua nastere orice cunoastere autentica si orice veritabila filozofie este eu-l cogitatiilor pure. Eu ma îndoiesc, deci cuget, cuget deci exist, este singura certitudine a mea, deorece este posibil ca ceva despre care cuget sa nu existe, dar nu este posibil ca îndoiala mea sa nu existe ca cugetare, deoarece ar fi absurd. Chiar daca as afirma ca eu cel care ma îndoiesc sunt inexistent, cel care afirma acest lucru sunt eu însumi, deci eu exist. Unicul teren ferm si care nu poate fi eliminat sunt eu cel care judec si astfel filozofia si-a dobandit cu adevarat libertatea sa, care rezida numai în propria sa gândire, orice alta autoritate sau prejudecata fiind excluse.Aceasta este imensa contributie pe care a adus-o Descartes la întemeierea subiectivitatii, libertatii si independentei ratiunii, surse primordiale pentru constituirea modernitatii. Criteriul adevarului se afla, începand din acest moment, doar în ratiunea însasi ca expresie 
a claritatii si distinctiei care trebuie sa o caracterizeze pentru a o conduce la cunoasterea evidenta. Indoiala metodica care conduce la certitudine, respectiv certitudinea existentei mele ca subiect ganditor liber si ideile clare si distincte sunt cele doua mari principii metodologice descoperite de catre Descartes.

Pe langa aceste doua principii, Descartes mai descopera si patru reguli care conduc bine ratiunea în demersul sau de cunoastere. Aceste reguli pot fi prezentate ca un proces de descompunere a lucrurilor în elementele lor simple care apoi se recompun prin deductie, aceasta mergând, potrivit exprimarii lui Descartes, din evidenta în evidenta si se ridica prin inductie la adevaruri generale. Astfel, Descartes a adus o contributie deosebita procesului complex de matematizare a cunoasterii prin folosirea deductiei si a inductiei, care se completeaza strâns împreuna. Nu se poate imagina matematica de astazi cu aplicatiile ei multiple fara fundamentul ei modern care porneste de la Descartes. Putem spune chiar ca Descartes este primul care încearca sa justifice ipotezele nu doar prin experienta ci si prin calculul matematic.

Putem vedea de asemenea în tratatul despre suflet, 'Les passsions de l'âme"' al lui Descartes începuturile psihologiei moderne. Descartes va clasa si defini pasiunile începând cu cele fundamentale (dragoste, ura, tristete, bucurie) pâna la cele morale, articulate pe principiul libertatii: prudenta, stiinta, generozitate. Contributia acestui ganditor la valoarea subiectului epistemic prin demnitatea ratiunii si cercetarea metodologica au avut o semnificatie fundamentala pentru constructia modernitatii.

Descartes a avut, catre sfârsitul evului mediu, un precursor care poate fi considerat primul filozof al Renasterii in persoana lui Nicolaus Cusanus (14411464). Acesta se opune cu determinare logicii scolastice, al carei criteriu de adevar era non contradictia, explicând în mod speculativ accesul cunoasterii intelectuale la un adevar mai adânc, care integreaza aparentele opozitii prin conceptul de coincidentia opozitorium. Astfel, în Dumnezeu, care este infinit, contradictiile finite dispar, el fiind maximum si minimum, niciunde si peste tot. Cusanus anticipeaza astfel dialectica speculativa a unitatii contrariilor din marele sistem speculaiv hegelian.

Modernitatea se naste desigur si cu aparitia noului spirit stiintific capabil sa rastoarne pozitia noastra în univers. Geocentrismul Sfintelor Scrieri este înlocuit de catre Nicolas Copernic (14731543) cu heliocentrismul, în care acum Pamântul se invarteste în jurul Soarelui. Dar noua orientare epistemologica vine odata $\mathrm{cu}$ publicarea lucrarii lui Galileo Galilei: 'Mesajul celest'" (1610), în care el arata ca marea carte a naturii este scrisa prin caractere matematice. 'S'opére alors pour la première fois dans l'humanité, la jonction de la science de la nature et de l'intelligibilité mathématique, qui sera le fondament de la science experiementale.", . Universul naturii este deci începând de acum un întreg deschis de legi caruia matematica si teoria ei îi poate explica fenomenalitatea. $\mathrm{Nu}$ exista pentru Galilei o ruptura între lumea fenomenala si cea noumenala, ceva care ar exista în sine si la care experienta bine condusa de catre inteligenta umana nu ar avea acces. In plus, pâna în acea epoca, teoria vitalista a lui Aristotel atribuia regnului viu o forta vitala imposibil de sesizat pe cale experimentala. Galilei sustine ca si ceea ce este de natura vie poate fi explicat prin legile fizicii, deoarce si aceste tipuri de fenomene au o cauza si un efect care sunt susceptibile de a fi cunoscute potivit acestor legitati, cauzaefect. Importanta lui Galilei este deosebita pentru începuturile modernitatii si pentru faptul ca "el aplica efectiv matematica în cercetarile experimentale, conjugand astfel rationamentul deductiv cu cel inductiv".

Odata cu Critica ratiunii pure a lui Kant (1724-1804), limitele cunoasterii sunt din 
nou reduse la fenomenalitatea lumii. Lucrul în sine, desi exista potrivit lui Kant, ramâne un deziderat incognoscibil pentru ratiunea umana. Kant ridica problema cunoasterii lucrului în sine, adica a noumen - ului care se ascunde în fenomen-si deci implicit posibilitatea fundamentarii metafizice- prin metoda judecatilor sintetice a priori, dar a carei caracteristica nu conduce nici ea la cunoasterea acestui tip de enigma, numit lucru în sine. Aceasta datorita faptului ca si asemenea judecati intuitive sunt condamnate sa ramâna în cadrul spatiotemporal al carui univers nu apartine lucrului în sine. Daca am fi capabili sa transgresam spatiul si timpul ca forme pure ale intuitiei sensible prin intermediul unei intuitii suprasensibile, dar de care în fapt noi nu dispunem, numai atunci am avea acces la o realitate absoluta care însa, în fapt, ne depaseste continuu.

Sa precizam totusi ca prin contributia lui Kant, modernitatea si-a sumat maniera critica de a sonda antinomiile ratiunii cât si problemele care decurg de aici. Metoda critica pe care modernitatea si-a asumat-o astazi în privinta întregii problematici care decurge din însasi radicalitatea schimbarilor pe care le suferim, acesta metoda de abordare, îsi are fundamentul în criticismul kantian. Ca acest aspect nu se produce întotdeauna astazi de o maniera constructiva este o provocare careia trebuie sa-i facem înca fata.

Am vazut ca progresul în spatiul epistemologic de cunoatere este relativizat de catre Kant datorita imposibilitatii de aprehendare a lucrului în sine. Însa, în spatiul ratiunii practice, potrivit lui Kant, nu avem nici o limita, deoarece avem legea morala proprie, întemeiata în mod categoric pe vointa noastra autonoma, capabila sa atinga perfectiunea morala. Posibilitatea perfectiunii este data tocmai de existenta imperativului categoric $\mathrm{cu}$ valabilitate universala: sa actionam astfel încat maxima vointei noastre sa poata oricând valora în acelasi timp ca principiu al unei legislatii universale. Desi suntem cu totii si fiinte sensible si tocmai prin acesta putem gresi fata de legea morala, valabilitatea ei ramâne neatinsa, deoarece forma în care a fost enuntata este o maxima cu valoare universala. Cum putem pune în practica o asemenea lege? Prin actiuni care sa vizeze omul ca scop în sine si mai mult chiar, ca scop final al naturii. Sa precizam totusi ca scop final al naturii înseamna, în viziunea ecologista de astazi, ca noi suntem responsabili fata de protectia acesteia, doarece numai noi avem constiinta acestei responsabilitati, ceea ce natura nu are cu necesitate în structura sa. Omul este scop în sine prin faptul ca-si respecta semenul în demnitatea lui absoluta, iar natura, ca sursa a vietii cu care coabiteaza armonios.

Ce însemna în fapt sa te comporti liber, o notiune atât de pretioasa modernilor, societatilor care se pretind avansate? Datorita constiintei morale, orice fiinta umana are acces la producera binelui pe care-l gaseste în maretia indestructibila a libertatii sale împlinite. Astfel, numai o fiinta umana care îsi apara, îsi cultiva si îsi pune în practica esenta demnitatii sale este o fiinta libera. Calea care conduce catre fundamentul lucrurilor nu este ceva care penetreza lumea din afara catre o presupusa esenta a ei, ci cea care pleaca din interiorul nostru pentru o mai buna constientizare. Putem spune chiar ca individul devine persoana exact în momentul în care pune în act potentialul constiintei pe care o poseda în sine.

Odata cu intrarea în arena a filozofiei hegeliene, deosebirea dintre o lume care ar ascunde în ea un oarecare lucru în sine si exerioritatea ei exprimata prin fenomenalitate, nu mai este acceptata. $\mathrm{Nu}$ exista nimic în natura sau în spiritul uman care sa se ascunda în sine pentru simplul motiv ca ceeea ce urmarim sa cunoastem este purul adevar si nu ceva dedublat cum ar fi lucrul în sine la care spiritul nostru nu ar avea acces. Porivit lui Hegel, nu se poate argumenta existenta a ceva care ar ramâne 
în sine, din moment ce cunoasterea nu poate sa spuna nimic despre acel în sine, asa cum nu se poate admite nici existenta lui Dumenzeu daca spiritul uman nu poate spune ceva determinant depre acel Dumnezeu. Problema care se punea si pentru Hegel era de a arata cum e posibil pentru noi ca fiinte subiective, ca eu-uri care gândim sa formulam totusi judecati obiective. Hegel spune ca despasim acest solipsism prin capacitatea de a gândi gândul, obiectualizând astfel propria gândire. Omul modern crestin, asa cum îl percepea Hegel, era acum cel care putea sa sesizeze adevarul unitatii între natura sa divina si umana si tocmai realizarea acestei naturi nascute într-o asemenea credinta îi da certitudinea ca este nascut în libertate. Dumnezeu, prin persoana lui Iisus, nu mai este acea alteritate transcendenta, ci este acum prezenta si actiune vie în spiritul omului. Dumnezeu nu mai este doar un postulat al ratiunii practice cum era la Kant, ci si o manifestare accesibila pentru ratiunea speculativa si teoretica. Punctul culminant al idealismului absolut hegelian este concluzia ca o ratiune finala este în miezul procesualitatii istorice, deasupra tuturor precaritatilor aparente. Hegel vede etapele de constituire a modernitatii printro progresiva consti-entizare a libertatii care se împlineste prin forma sa ideal realizata.

La început, despotismul oriental afirma doar ca un singur om este liber: forma singularitatii. Conducerea aristocratiei greco-romane recunostea doar libertatea unora: forma particularitatii. Sosirea crestinismului aduce cu sine libertatea tuturor oamenilor, recunoscând omul ca fiinta umana în sine libera: universalul abstract. Ultima etapa este aceea a edificarii statului modern în care omul devine liber efectiv si concret prin unitatea libertatii sale individuale $\mathrm{cu}$ colectivitatea careia îi apartine: universalul concret. Cum am spune noi cei de astazi, fericirea libertatii individuale se realizeza pe sine doar în cadrul propice al unui stat de drept în care libertatea fiecaruia este garantata prin institutiile sale.

Se formuleaza astfel explicit, pentru prima data în istoria umanitatii, o jonctiune între libertatea individuala si cea colectiva, libertatea fiecarui cetatean având drept de exprimare în cadrul legiferat al unui stat modern, si ale carui institutii garanteaza totodata dreptul la libera exprimare.

Programul modernitatii initiat de Descartes si continuat de catre Kant si Hegel arata ca orice filozofie trebuie sa fie ancorata în libertatea subiectului uman, care prin ratiune si moralitate sa fie un exemplu pentru edificarea unei lumi.

Mai tarziu, acest proiect continuat si de catre alti filozofi pe care nu am avut posibilitatea sa-i presentam aici din lipsa de spatiu- si care ajunge la Kant si Hegel este considerat totusi de catre Husserl un act neîmplinit. In primul rând, potrivit lui Husserl, în pofida sistemului idealist absolut hegelian, ceea ce i se poate reprosa acestuia este lipsa de critica a ratiunii, conditie necesara stiintificitatii oricarei filozofii. Husserl nu a încercat sa valorifice sistemul de gândire hegelian, asa cum face de pilda cu cele ale lui Descartes si I. Kant.

In al doilea rând, conform lui Husserl, proiectul initiat de obiectivitatea stiintifica ajunge sa devina unilateral si sa piarda legatura cu subiectul, cu constiinta, cu ceea ce initiatorul fenomenologiei transcendentale post hegeliene numeste lebenswelt. Obiectivismul naiv al stiintei acelor vremi risca sa ramâna în limitele naturii, obiectului si ale cantitatii. Stiinta s-a separat de problemele autentice ale omului care nu pot fi revigorate decât printr-o fundamentala întoarcere la o filozofie a spiritului. $\mathrm{O}$ asemenea grandioasa întreprindere însemna fundamentarea unei filozofii radicale pe care Husserl o va preconiza ca o noua metoda fenomenologica în care subiectul constient de sine se va împlini prin raportul cu semenii sai în cadrul comunitatii. Acest scop nu va fi împlinit câta vreme filozoful nu se va oglindi pe sine ca fiinta rationala, 
ca traitor purtator de logos, ca functionar în slujba umanismului. Pentru aceasta, este nevoie de o noua constiinta care sa puna în valoare structuri stabile si fundamentale, dincolo de interesele particulare ale unei constiinte limitate. Desigur, orice tip de constiinta este pentru Husserl o constiinta despre ceva. Dar trebuie largit continutul cogito-ului transcendental astfel încat acesta sa poarte în el propriul sau cogitatum, propriul sau obiect al gândirii.

Calea de cunoastere si de întemeiere autentica a oricarei lumi mai bune pleaca si pentru Husserl de la ego cogitu-ul cartezian, se adânceste într-o reflectie de sine universala, împlinindu-se în intersubiectivitatea transcendentala. Tema initiala era întoarcerea de la obiectivismul naiv al stiintelor si al psihologiei la subiectivismul transcendental al filozofiei responsabile. Aceasta responsabilitate era initiata de catre îndoiala si punerea între paranteze (epoché) a lumii sensibile cât si a judecatilor filozofice despre acesta lume. Tocmai aceasta punere între paranteze a lumii, aceasta eliminare a tuturor detaliilor insignifiante îl face pe Husserl sa afirme ca în acest fel ma descoper pe mine ca eu mai profond, ca subiect pur sau eu transcendental. Aceasta mare descoperire îi revenea deja lui Descartes ca initiator al fundamentului prim pentru orice fel de cunoastere; dar potrivit remarcilor lui Husserl, Descartes a gresit ulterior, deoarece ajunge sa deduca existenta lui Dumnezeu si astfel tot ceea ce exista, din principiile înnascute ale eu-lui. De fapt, Descartes ar fi trebuit sa deduca existenta si determinatiile acesteia din ceea ce i-ar fi fost dat în mod real si nemijlocit lui ego cogito.

$\mathrm{Nu}$ vom mai urmari demonstratiile deosebit de complexe si profunde ale lui Husserl pâna la constituirea intersubiectivitatii transcendentale. Vom retine din stradania lui de constituire a intersubiectivitatii importanta acesteia pentru lumea de azi de a pune în practica comunicari de constiinte capabile sa fundamenteze coexistenta terestra. Vom mai retine din filozofia lui necesistatea imperioasa pentru noi, de constituire transcendentala a unei lumi al carei sens si origine se impun a fi clare si responsabile. Vom putea sesiza mai bine si clarifica marile probleme ale mondializarii, problema ecologica, a foametei, a pacii, a tehnostiintei, a banilor, a informatiei, a internetului- si asa mai departe- numai dupa ce vom plasa toate acestea în spatiul pur al unei reflectii de sine universale, care sa ne indice sensul si posibilitatea unei vieti umane autentice.

Cel mai de seama elev al lui Husserl, Martin Heidegger reorienteaza fundamentarea filozofiei catre solul gândirii originare, acolo unde adevarul era înteles ca aletheia, ca stare de ne-ascundere care s-a refuzat pâna azi determinarii filozofiei moderne. Eroarea s-a produs, crede Heidegger, deoarece toti predecesorii sai au gândit cautarea adevarului din perspectiva corectitudinii, pe când sarcina întemeierii unei lumi mai bune ar trebui fundamentatata pe regândirea fiintei, asa cum se afla ea în puritatea ei presocratica. Acest început presocratic reprezinta în viziunea lui Heidegger un moment privilegiat în care fiinta se poate arata ca Lichtung, ceea ce pentru Heidegger însemna deschidereluminatoare. Activitatile creatoare ale omului nu-si vor gasi adâncimea ideatica a scopului atâta vreme cât nu se vor orienta catre deschiderea luminatoare, care este fiinta însasi, temeiul oricarei creatii 'rationale'.

Sa mai precizam ca Heidegger vede în notiunea de khora a lui Platon, prefigurarea subiectului cartezian, în sesnsul ca fiintarea devine ceea ce este ea însasi prin capacitatea noastra de reprezentare. Aceasta capacitate de reprezentare va deveni marca determinata pentru modernitate. Ea este metoda fundamentala 
de cunoastere a diversitatii lumii cât si o maniera generala de a se întelege pe sine.

Kant vorbise déjà despre reprezentare ca despre ceva ce însoteste actul gândirii. Caci daca ar fi altfel, reprezentarea n-ar putea fi gândita. Acesta reprezentare care apare în gândire se numea intuitie. Ea este un act spontan al gândirii mele care transcende domeniul sensibilitatii.Reperezentarea este pentru lumea moderna un mijloc prin care fiinta si fiintarea se determina reciproc strabatând domeniile culturii, politicii, economiei, tehnicii, istoriei, etc.

Toate aceste domenii îi apar modernului ca un izvor de care poate dispune, potrivit puterii sale cu ajutorul careia si-a propus sa cucereasca lumea. Insa tocmai în acest proiect rezida si riscul umanitatii, deoarece o asemenea demiurgie fara egal în istoria noastra risca sa ne depaseasca prin adâncimea si amploarea lor.

Intrebat deja în 1966, într-un interviu în Der Spiegel, daca poate indica o cale în fata provocarilor fara egal din lumea modernitatii, Heidegger raspunde ca filozofia nu poate pentru moment aduce o schimbare directa asupra starii actuale a lumii. Doar un Dumnezeu prezent, preciza filozoful, ar putea sa ne salveze.

Insa ca El sa fie prezent, precizam noi, e nevoie ca umanitatea ca destin luminator sa fie capabila sa structureze o asemea disponibilitate a întâlnirii. Daca suntem cu adevarat rangul cel mai înalt al creatiei divine, lumea în care traim ar trebui refondata din perspectiva transcendentei. Aceasta nu doar ar impiedica puterile noastre dezlantuite sa devina o maledictiune, într-o lume supra-echipata cu de toate, cât mai ales ar favoriza constructia a ceva trainic, potrivit unei logici a constientizarii, precautiei si responsabilitatii.

Toate acestea ar conduce catre o noua ontologie îndreptata catre fiinta, în care omul ar mijloci între un acelasi temei si scop care îl transcend. In acest sens, poate ca Dumnezeu nu este o transcendenta exterioara si inaccesibila, ci relatia intima din noi, care activeaza moralitatea si sensul lumii.

Bibliografie:

[1] Arendt, Hannah., Condition de l'homme moderne, Calmann-Levy, Paris1, 1983.

[2] Auroux, S., Les notions philosophiques, Presse Universitaire de France, Paris, Tome I, 1990.

[3] Aubert, Nicole., Le culte de l'urgence, Flamarion, 2003

[4] Baudrillard, J., Morin., E., La violence du monde, Le Félin et l'Institut du Monde Arabe, Paris, 2003.

[5] Bauman Z., Le coût humain de la mondialisation, Hachette Littératures, Paris, 1999.

[6] Beck, Ulrich., La societé du risque, sur la voi d'une autre modernité, Flamarion, Paris, 2001.

[7] Bedin, Veronique., Philosophies et pensées de notre temps, Sciences Humaines Éditions, 2011

[8] Castel, R., La gestion des risques, Minuit, Paris, 1982

[9] Cassirrer, Ernst., Eseu despre om. O introducere în filozofia culturii umane. Editura Humanitas, Bucuresti, 1994.

[10] Descartes, René., Régles pour la direction de l'esprit, Vrin, 1970

[11] Descartes, René., Discours de la methode, suivi des Meditations, Paris, 1951

[12] Descartes René., Les passions de l'âme, Le livre de Poche, 1990.

[13] Dortier, Jean-Franç̧ois, Philosophies de notre temps, Sciences Humaines Éditions, 2000.

[14] Dupont, Y., Dictionnaire des risques, Armand Colin/VUEF, Paris, 2003,

[15] Douglas, M., Wildavsky A., Risk and Culture, University of California Press, 1983.

[16] Ehrenberg, A., Le culte de la performance, Calmann-Lévy,Paris, 1991.

[17] Elias, N., Uber den Process der Zivilization, éd de poche, Surhkamp, Frankfurt, 1972.

[18] Febvre, L., Civilisation: évolution d'un mot et d'un group d'idées, 1930, in pour une histoire a apart entière, Sevpen, Paris, 1962

[19] Folscheid, Dominique., Les grandes dates de la philosophie clasiquee, moderne et contemporaine, PUF, Paris, 1996.

[20] Habermas, Jurgen., Le discours philosophique de la modernité, Éditions Gallimard, 1998 
[21] Hottois, Gilbert., De la Renaissance à la Postmodernité, Éditions De Boeck Université, 2002.

[22] Graf, Alain., Les grands courants de la philosophie moderne, Éditions de Seuil, février 1996.

[23]Hegel, G.W.F., Fenomenologia spiritului, Editura Academiei Republicii Poplare Romane, Bucuresti, 1965.

[24] Hegel, G.W.F., Stiinta logicii. Traducere de D.D. Rosca. Editura Academiei, Bucuresti, 1966.

[25] Hegel, G.W.F., Prelegeri de filozofie a istoriei, Traducere de petru draghici si Radu Stoichita, Editura Academiei, Bucuresti, 1968.

[26] Huisman, Denis., Socrate sur Internet, Éditions de Fallois, 1997.

[27] Husserl, Edmund., Meditatii carteziene, O introducere în fenomenologie, Traducere, cuvânt înainte si note de Aurelian Craiutu, Humanitas, Bucuresti, 1994

[28] Husserl, Edmund., Cercetari logice, vol. I si II, Traducere, traducere din germana de Bogdan Olaru, Humanitas, Bucuresti, 2007

[29] Husserl, Edmund., Filozofia ca stiinta riguroasa, Traducere, postfata, note si comentarii de Alexandru Boboc Paideia, 1994

[30] Husserl, Edmund., La crise des sciences européenes et la phenomenologie transcendantale, traduit de l'allemand et préface par Gérard Granel, Gallimard, 1976

[31] Heidegger, M., Fiinta si Timp, Humanitas, Bucuresti, 2003.

[32] Heidegger, M., Lettre sur l'humanisme. In Quiestion III ,Gallimard, Paris, 1946.

[33] Heidegger, M., Repere pe drumul gândirii. Traducere si note introductive de Thomas Kleininger si Gabriel Liiceanu. Editura politica, Bucuresti, 1988.

[34] Heidegger, M., Introducere în metafizica. Traducere din germana de Gabriel Liiceanu si Thomas Kleininger. Editura Humanitas, Bucuresti, 1999.

[35] Jaspers, K., La bombe atomique et l'avenir de l'homme, Buchet-Chastel, Paris, 1963.

[36] Kant, Immanuel., Critica ratiunii pure. Traducere de Nicolae Bagdasar si Elena Moisuc. Studiu introductiv, glosar kantian si indice de nume proprii de Nicolae Bagdasar. Editura stiintifica, Bucuresti, 1969.

[37] Kant, Immanuel., Critica ratiunii practice. Traducere, studiu introductiv, note si indici de Nicolae Bagdazar. Editura stiintifica, Bucuresti, 1972.

[38] Kant, Immanuel., Prolegomene la orice metafizica viitoare care se va putea înfatisa drept stiinta. Traducere de Mircea Flonta si Thomas Kleininger. Studiu introductiv si note de Mircea Flonta. Editura stiintifica si enciclopedica, Bucuresti, 1987.

[39] Lipovetsky, G., L'ère du vide, Gallimard, Paris, 1983.

[40] Mayet, Laurent., Le monde selon les grands penseurs actuels, Éditions Scali, 2007.

[41] Marange, V., La Bioétique, la science contre la civilisation ?, Le Monde Poche, Paris, 1998.

[42] Monique Canto-Sperber, Dictionnaire d'étique et de philosophie morale, volume I et II, PUF, 1996.

[43] Morin, Edgar., Gândind Europa, Editura Trei, 2002

[44] Noica, C., Modelul cultural european, Humanitas, Bucuresti, 1993.

[45] Noica, C., Doua tratate filozofice, Viata si filosofia lui René Descartes,

[46] Noica,C., Sase maladii ale spiritului contemporan, Editura Univers, Bucuresti, 1978.

[47] Piotte, Jean-Marc., Les neufs clées de la Modernité. Éditions Québec Amerique, Montréal, 2001

[48] Renaut, Alain., Naissances de la modernité, Tome II, Calman-Lévy, 1999.

[49] Russ, Jacqueline., La marche des idées contemporaines, Armand Colin Éditeur, Paris, 1994.

[50] Savater, Fernand, Penser sa vie. Éditions du Seuil, septembre 2000.

[51] Sloterdjik, P., La mobilisation infinie, Christian Bourgois, Paris, 2000.

[52] Sapontzis, S. F., Moral value and reason, monist 1983, 66. n 1, Right reason in western ethics,

[53] Virilio, P. La bombe informatique, Galilée, Paris, 1998. 